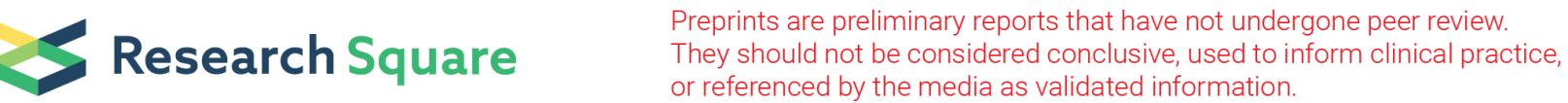

\section{Upper Limb Sensory Evaluations in Women With Breast Cancer Related Lymphedema Receiving Complex Decongestive Physiotherapy: An Ultrasonographic Study}

\section{Emine Baran ( $\nabla$ eminekbaran@gmail.com )}

Hacettepe University: Hacettepe Universitesi https://orcid.org/0000-0003-4974-6543

\section{Levent Özçakar}

Hacettepe University: Hacettepe Universitesi

Serap Özgül

Hacettepe University: Hacettepe Universitesi

\section{Sercan Aksoy}

Hacettepe University: Hacettepe Universitesi

\section{Türkan Akbayrak}

Hacettepe University: Hacettepe Universitesi

\section{Original Article}

Keywords: Lymphedema, Semmes-Weinstein, two-point discrimination, pressure pain threshold, tactile localization, ultrasound

Posted Date: February 17th, 2021

DOI: https://doi.org/10.21203/rs.3.rs-200901/v1

License: (c) (i) This work is licensed under a Creative Commons Attribution 4.0 International License.

Read Full License 


\section{Abstract}

Purpose: The aim of this study was to investigate if/how the presence of lymphedema affected the sensation of the upper limb, and to assess whether complex decongestive physiotherapy (CDP) had a favorable impact on the sensory testings.

Methods: A total of 27 patients with unilateral stage 2 breast cancer related lymphedema (BCRL) were included in the study. Bilateral ultrasonographic (epidermis, dermis, and subcutaneous fat thicknesses) and circumferential measurements were peformed at $10 \mathrm{~cm}$ distal to the elbow crease. SemmesWeinstein monofilament (SWM), static and moving two-point discrimination, pressure pain threshold (PPT) and tactile localization tests were also applied at the same site. After their initial evaluation, all patients underwent CDP phase 1 program (five times a week, for three weeks). All the evaluations were repeated at the end of their treatment as well.

Results: Before CDP, affected sides had significantly higher values than the unaffected sides in terms of SWM $(p<0.001)$, static $(p=0.002)$ and moving two-point discrimination $(p=0.011)$, PPT $(p=0.001)$, and tactile localization $(p<0.001)$ values. After CDP, SWM $(p=0.002)$, static $(p=0.009)$ and moving two-point discrimination ( $p=0.024)$, PPT $(p=0.014)$ and tactile localization $(p<0.001)$ values decreased significantly on the affected sides.

Conclusion: BCRL seem to reduce light touch, static and moving two-point discrimination, PPT and tactile localization sensations whereas CDP seems to improve these sensory perceptions in women with BCRL. Of note, ultrasonographic measurements also appear to be promising for prompt and convenient follow up in the management of these patients.

\section{Clinical Trial Registration Number: NCT04296929}

Date of registration: March 5, 2020

\section{Introduction}

With the therapeutic advances, the survival rates as well as certain long-term complications have increased among breast cancer survivors. For instance, breast cancer related lymphedema (BCRL) is commonplace in musculoskeletal practice and has the potential to cause significant disability during daily activities [1]. Herewith, in addition to lymphedema, breast cancer patients might also suffer other conditions (e.g. sensory disturbances due to neuropathic problems after surgery, radiotherapy or chemotherapy) that contribute to patients' particular complaints like arm pain, numbness or feeling of heaviness, etc. [2,3]. While there are already/several studies in the literature on physical, functional, emotional problems; the effects of lymphedema on sensory parameters have not been explored until now. Accordingly, the purpose of this study was two-fold; first, we aimed to investigate if/how the presence of lymphedema did affect the sensation and second, we aimed to assess whether complex decongestive physiotherapy (CDP) had a favorable impact on sensory testings. To this end, aside from circumferencial 
measurements and sensory evaluations (light touch, static and moving two-point discrimination, pressure pain threshold sensation perceptions), we also included ultrasonographical (i.e. morphological) evaluations of different layers of skin and subcutaneous tissues in this study.

\section{Materials And Methods}

\section{Subjects}

Between November 2019 and November 2020, women with stage 2 unilateral BCRL (with at least $2 \mathrm{~cm}$ difference in arm circumference) who had completed active breast cancer treatment at least 12 months before were recruited for the study if they were at least 18 years old and literate as well. They were excluded in the presence of any of the followings: current recurrence of breast cancer, bilateral involvement, smoking, diabetus mellitus, pre-existing neuromusculoskeletal conditions that would affect (local) upper limb testing, edema due to other reasons (e.g. primary lymphedema, heart, kidney or liver diseases, filariasis), contraindications for CDP (e.g. deep vein thrombosis, thrombophlebitis, cardiac edema, peripheral artery disease, active infection and scleroderma), analgesic use in the last 24 hours and previous treatment for lymphedema in the last 12 months.

The study protocol was approved by the Local Ethics Committee (Date: 28.11.2019, No: KA - 19120) of our university and all subjects gave written informed consent based on the principles set out in the Helsinki Declaration.

\section{Assessment and Outcome Measures}

This study utilized a prospective study design. A socio-demographic and clinical questionnaire was used to collect information on age, height, weight, health, education, smoking habit, medications and concomitant diseases. Ultrasonographical evaluations, circumferential measurements and sensory tests were applied bilaterally before and three weeks after CDP.

\section{Circumference Measurements}

A flexible tape was used to measure the circumferences at the wrist (ulnar styloid) and at each 5-cm segment until the axilla. Measurements were taken horizontally using a slight pressure. Volume was calculated bilaterally from circumference values using the truncated cone formula - which yielded excellent inter- and intra-observer reproducibility in comparison to water displacement [4]. Lymphedema severity was determined according to the volumetric difference between the affected and unaffected limbs [5].

\section{Sensory Testing}

During the sensory tests, participants were seated with their forearms supinated and extended on the examination table. They were informed in details about the tests before the assessments. The patients were asked to close eyes and turn the head towards the opposite side of the testing arm. After 3-weeks of CDP treatment, at the last day of the study; the compression bandages were removed and, before the 
sensory measurements, patients were asked to wash their arms, lie down and rest for 30 minutes in order to reduce the effect of compression on sensory perception. As being one of the most objective sensory tests [6, 7], Semmes-Weinstein monofilaments (SWM) (North Coast Medical, Morgan Hill, CA) were used to assess tactile sensitivity of the upper extremities - volar region of the forearm, $10 \mathrm{~cm}$ distal to the midpoint of the medial and lateral epicondyles. The tests were started with the smallest diameter monofilament and progressed successively with larger diameter monofilaments, until the correct responses were obtained [6, 7]. Each monofilament was touched three times with $2 \mathrm{sec}$ intervals and the patients were asked to say 'yes' when they felt the monofilament on their skin.

Static two-point discrimination test was performed with an estesiometer, in the volar region of the forearm (between the regions $8-12 \mathrm{~cm}$ distal to the midpoint of the medial and lateral epicondyles). The test was started with a $5 \mathrm{~mm}$ gap between the tips of the estesiometer. For the two-point discrimination, the tip was tapped randomly in the test area, either single or double. When the skin was touched at two points, care was taken to apply simultaneous and equal pressure. A resting time of 2 seconds was given between each application. When seven out of 10 responses of the patient were correct, the answer was considered correct. In case of incorrect answers, the test was continued until the correct answer was reached by increasing the distance between the two ends of the estesiometer by $5 \mathrm{~mm}$. The lowest range value that the patient knew correctly was recorded in $\mathrm{mm}[8,9]$.

Similarly, moving two-point discrimination test was also performed with an estesiometer between the regions of the upper extremity, in the volar region of the forearm 8-12 cm distal to the midpoint of the medial and lateral epicondyles. The tips of the estesiometer - placed as one or two points - were moved from proximal to distal. If seven of the 10 responses given by the patient were correct, the test was considered correct. If the answer was wrong, the gap between the tips of the estesiometer was increased by $5 \mathrm{~mm}$ until the right answer [10].

Pressure pain threshold (PPT) measurement was assessed with an algometer ( $\mathrm{J}$ tech Algometer Commander) on both upper extremities, in the volar region of the forearm $10 \mathrm{~cm}$ distal to the midpoint of the medial and lateral epicondyles. With the $1 \mathrm{~cm}^{2}$ head of the algometer, pressure was applied vertically and the patient was asked to say 'yes' when he/she felt uncomfortable with the pressure. The measurement was repeated three times and PPT values were recorded by taking the arithmetic mean of three trials [11].

Tactile localization test was evaluated in the volar region of the forearm 8-12 cm distal to the midpoint of the medial and lateral epicondyles, using a pencil and ruler. The eyes of the patient were closed and the body surface was touched with a pencil. The patient was asked to open his eyes and show the point that was touched. The distance between the point actually touched and the point indicated by the patient was measured with a ruler in $\mathrm{cm}$ and recorded. A total of three measurements were done and values were recorded by taking the arithmetic mean of the three trials $[12,13]$.

\section{Ultrasonographic Measurements}


Ultrasound (US) imaging was performed using a 5-12 MHz linear probe (Logiq P5, GE Medical Systems, Wisconsin, USA) and all the measurements were done by a single physiatrist - with more than 20 years of expertise in musculoskeletal US (LÖ). During the procedure, participants were seated with their forearms supinated and extended on a pillow. At $10 \mathrm{~cm}$ distal to the elbow crease, along the line parallel to the arm axis from the midpoint of the medial and lateral epicondyles, the measurements were performed bilaterally [14]. Epidermis, dermis, and subcutaneous fat were measured by using plenty of gel and with minimum probe compression - using the automatic calculation feature of the US device.

\section{Complex Decongestive Physiotherapy}

After their initial evaluation, all patients underwent CDP phase 1 program for BCRL which comprised skin care, manual lymphatic drainage (MLD), compression bandages and exercises as recomended by the International Society of Lymphology consensus [15]. CDP was applied by a qualified physiotherapist five times a week, for three weeks (a total of 15 sessions, 60 minutes per session). MLD was applied using the Földi method and was followed by daily multi-layered short strech bandaging worn for 23 hours a day (excluding the 1-hour treatment session). Abdominal breathing exercises and remedial exercises were performed with the bandages on. Participants were advised to avoid cutaneous effractions (e.g. insect bite, cut, burn) and to protect their skin during daily activities (e.g. using a thimble when sewing) $[16,17]$.

\section{Statistical Analysis}

Statistical analyses were performed using the Statistical Package for the Social Sciences software, version 21.0 (IBM SPSS Statistics; IBM Corporation, Armonk, NY, USA). Normal distribution of the variables was tested by Kolmogorov-Simirnov/Shapiro-Wilk's test. Descriptive statistics are presented with mean and standard deviation for normally distributed numerical variables. Median and interquartile width values were used for non-normally distributed numerical variables while numbers and percentages were used for categorical variables. Wilcoxon test was applied to compare the affected vs. unaffected sides and pre- vs. and post-treatment values. Mann-Whitney $U$ test was applied to compare data pertaining to dominant vs. non-dominant upper limb involvement. Correlation analyses between skin thickness measurements (epidermis, dermis and subcutaneous fat) and sensory tests (SWM, static and moving two-point discrimination, PPT and tactile localization) were done using Spearman correlation coefficients. Statistical significance was set at $p<.05$. Power analysis was done using GPower program. The post-hoc power analysis $(\mathrm{N}=27)$ of the Wilcoxon test for SWM values between the pre- and posttreatment results of the affected sides achieved a power of $98 \%$ with a significance level of 0.002 .

\section{Results}

A total of 42 subjects applied for lymphedema treatment. Of those, two were found to have bilateral mastectomy, two had smoking history, one had diabetus mellitus, one had upper extremity infection, one was diagnosed with recurrent ipsilateral breast cancer, three had stage one lymphedema and five subjects could not complete the treatment/assessments (due to COVID 19 pandemic). Eventually, 27 participants were enrolled and completed all the procedures. Clinical characteristics of the subjects are 
given in Table 1. Before the CDP, all the circumference and ultrasonographical measurements were found to be higher $(p<.05)$ in the affected limbs (Table 2). After the CDP, while circumference and ultrasonographical measurements (except epidermis) decreased significantly on the affected sides $(p<$ $0.001)$, they remained the same on the unaffected sides $(p>.05)$ (Table 3 ).

Table 1

Socio-demographic and clinical characteristics of the subjects $(\mathbf{N}=$ 27)

\begin{tabular}{|ll|}
\hline Age (year) & $\mathbf{5 9 . 1} \pm \mathbf{8 . 5 6}$ \\
\hline BMI (kg/m ${ }^{2}$ ) & $30.6 \pm 4.42$ \\
\hline Education (year) & $10.2 \pm 3.8$ \\
\hline Cancer diagnosis onset (month) & $84.7 \pm 38.9$ \\
\hline Lymphedema duration (month) & $49.8 \pm 35.1$ \\
\hline Lymphedema severity (moderate/severe) & $9 / 18$ \\
\hline Affected side (R/L) & $11 / 16$ \\
\hline Dominant Upper limb (Right) & 27 \\
\hline Radiotherapy (yes \%) & 25 (92.6\%) \\
\hline Chemotherapy (yes \%) & 24 (88.9\%) \\
\hline Type of operation & 6 \\
\hline Lumpectomy + ALND & 4 \\
\hline Radical mastectomy + ALND & 11 \\
\hline Modified radical mastectomy + ALND & 5 \\
\hline Breast conserving surgery + ALND & $21.4 \pm 7.6$ \\
\hline Removed lymph nodes (N) & \\
\hline Data are presented as mean \pm standard deviation or number (\%) & \\
\hline BMI: Body mass index, ALND: Axillary lymph node dissection \\
\hline
\end{tabular}


Table 2

Pre-treatment circumference and soft tissue thickness measurements

\begin{tabular}{|llll|}
\hline & $\begin{array}{l}\text { Affected Side } \\
(\mathbf{N}=\mathbf{2 7})\end{array}$ & $\begin{array}{l}\text { Unaffected Side } \\
(\mathbf{N}=\mathbf{2 7})\end{array}$ & $\mathbf{p}$ \\
\hline Circumference $(\mathbf{c m})$ & $28.4 \pm 3.1$ & $23.3 \pm 2.3$ & $<0.001^{\star}$ \\
\hline Soft tissue thickness $(\mathrm{mm})$ & & & $0.023^{*}$ \\
\hline Epidermis & $0.041 \pm 0.013$ & $0.034 \pm 0.008$ & $<0.001^{\star}$ \\
\hline Dermis & $0.24 \pm 0.05$ & $0.1 \pm 0.022$ & $<0.001^{\star}$ \\
\hline Subcutaneous fat & $1.44 \pm 0.4$ & $1.01 \pm 0.28$ & \\
\hline $\begin{array}{l}\text { Measurements pertain to a site } 10 \mathrm{~cm} \text { distal to the elbow and data are presented as mean } \pm \text { standard } \\
\text { deviation }\end{array}$ & & \\
\hline $\begin{array}{l}* \\
\text { ( }) \text { statistically significant difference between the affected and unaffected sides }\end{array}$ & \\
\hline
\end{tabular}

Table 3

Pre- and Post-treatment circumference and soft tissue thickness measurements

\begin{tabular}{|c|c|c|c|}
\hline & $\begin{array}{l}\text { Pre-treatment } \\
(\mathrm{N}=27)\end{array}$ & $\begin{array}{l}\text { Post-treatment } \\
(\mathrm{N}=27)\end{array}$ & $\mathbf{p}$ \\
\hline \multicolumn{4}{|l|}{ Affected Side } \\
\hline Circumference (cm) & $28.4 \pm 3.1$ & $25.8 \pm 2.6$ & $<0.001^{*}$ \\
\hline \multicolumn{4}{|c|}{ Soft tissue thickness (mm) } \\
\hline Epidermis & $0.041 \pm 0.013$ & $0.04 \pm 0.009$ & 0.496 \\
\hline Dermis & $0.24 \pm 0.05$ & $0.18 \pm 0.41$ & $<0.001^{\star}$ \\
\hline Subcutaneous fat & $1.44 \pm 0.4$ & $1.22 \pm 0.36$ & $<0.001^{*}$ \\
\hline \multicolumn{4}{|l|}{ Unaffected Side } \\
\hline Circumference (cm) & $23.3 \pm 2.3$ & $23.5 \pm 2.3$ & 0.884 \\
\hline \multicolumn{4}{|c|}{ Soft tissue thickness (mm) } \\
\hline Epidermis & $0.034 \pm 0.008$ & $0.036 \pm 0.006$ & 0.134 \\
\hline Dermis & $0.1 \pm 0.022$ & $0.11 \pm 0.023$ & 0.449 \\
\hline Subcutaneous fat & $1.01 \pm 0.28$ & $1.00 \pm 0.3$ & 0.586 \\
\hline \multicolumn{4}{|c|}{$\begin{array}{l}\text { Measurements pertain to a site } 10 \mathrm{~cm} \text { distal to the elbow and data are presented as mean } \pm \text { standar } \\
\text { deviation }\end{array}$} \\
\hline
\end{tabular}


Before the CDP, affected sides had significantly higher values for SWM $(p<0.001)$, static $(p=0.002)$ and moving two-point discrimination $(p=0.011)$, PPT $(p=0.001)$, and tactile localization $(p<0.001)$ scores (Table 4). After the CDP, SWM $(p=0.002)$, static $(p=0.009)$ and moving two-point discrimination $(p=$ $0.024)$, PPT $(p=0.014)$, and tactile localization $(p<0.001)$ values were decreased significantly on the affected sides. Sensory test results remained the same on the unaffected sides after the $\operatorname{CDP}(p>.05)$ (Table 5).

Table 4

Pre-treatment sensory assessment

\begin{tabular}{|c|c|c|c|}
\hline & $\begin{array}{l}\text { Affected Side } \\
(\mathrm{N}=27)\end{array}$ & $\begin{array}{l}\text { Unaffected Side } \\
(\mathrm{N}=27)\end{array}$ & p \\
\hline Semmes-Weinstein Monofilament & $3.22(2.44-3.61)$ & $2.44(2.36-3.22)$ & $<0.001^{*}$ \\
\hline Static two-point discrimination (cm) & $3.5(2.5-4.5)$ & $3.0(2.5-3.0)$ & $0.002^{\star}$ \\
\hline Moving two-point discrimination (cm) & $2.5(2.0-3.5)$ & $2.5(2.0-2.5)$ & $0.011^{*}$ \\
\hline Pressure pain threshold (kPa) & $9.6 \pm 1.4$ & $8.5 \pm 1.2$ & $0.001^{\star}$ \\
\hline Tactile localization (cm) & $1.84 \pm 0.52$ & $1.45 \pm 1.37$ & $<0.001 *$ \\
\hline \multicolumn{4}{|c|}{ Data are presented as mean \pm standart deviation or median (interquartile range) } \\
\hline
\end{tabular}


Table 5

Sensory parameters before and after complex decongestive physiotherapy

\begin{tabular}{|llll|}
\hline & $\begin{array}{l}\text { Pre-treatment } \\
(\mathbf{N}=\mathbf{2 7})\end{array}$ & $\begin{array}{l}\text { Post-treatment } \\
(\mathbf{N}=27)\end{array}$ & $\mathbf{p}$ \\
\hline Affected Side & & & \\
\hline Semmes-Weinstein Monofilaments & $3.22(2.44-3.61)$ & $2.83(2.44-3.22)$ & $0.002^{\star}$ \\
\hline Static two-point discrimination (cm) & $3.5(2.5-4.5)$ & $3.5(3.0-3.5)$ & $0.009^{*}$ \\
\hline Moving two-point discrimination (cm) & $2.5(2.0-3.5)$ & $2.5(2.3-3.0)$ & $0.024^{\star}$ \\
\hline Pressure pain threshold (kPa) & $9.6 \pm 1.4$ & $8.7 \pm 1.2$ & $0.014^{\star}$ \\
\hline Tactile localization (cm) & $1.84 \pm 0.52$ & $1.76 \pm 1.32$ & $<0.001^{\star}$ \\
\hline Unaffected Side & & & \\
\hline Semmes-Weinstein monofilaments & $2.44(2.36-3.22)$ & $2.44(2.36-2.83)$ & 0.149 \\
\hline Static two-point discrimination (cm) & $3.0(2.5-3.0)$ & $3.0(2.5-3.0)$ & 0.132 \\
\hline Moving two-point discrimination (cm) & $2.5(2.0-2.5)$ & $2.0(2.0-2.5)$ & 0.366 \\
\hline Pressure pain threshold (kPa) & $8.5 \pm 1.2$ & $8.3 \pm 1.6$ & 0.101 \\
\hline Tactile Localization (cm) & $1.45 \pm 1.37$ & $1.16 \pm 0.41$ & 0.301 \\
\hline Data are presented as mean \pm standart deviation or median (interquartile range) & \\
\hline (*) statistically significant difference between the affected and unaffected sides & \\
\hline
\end{tabular}

When the participants were grouped according to the involvement of their dominant vs. non-dominant upper limbs, there was no statistically significant difference in terms of SWM, static and moving twopoint discrimination, PPT and tactile localization values $(p>.05)$. Correlation analyses could not find any significant relationship between skin thickness measurements (epidermis, dermis, and subcutaneous fat) and sensory tests (SWM, static and moving two-point discrimination, PPT and tactile localization) (all $p$ $>$.05).

\section{Discussion}

The results of this study has shown that ipsilateral upper extremity sensory perception is decreased in women with BCRL and that CDP improved the light touch, static and moving two-point discrimination, PPT and tactile localization sensory perceptions. To the best knowledge of the authors, this study is the first to explore the relationship between ultrasonographic skin thickness measurements and sensory perceptions, and the effects of CDP on the changes in sensory evaluations. 
Limited studies in the literature mentioned the changes in sensory functions after breast cancer treatments. Smoot et al. [2] evaluated light touch using SWM and vibration with BioThesiometer in breast cancer patients with or without lymphedema whereby the severity of lymphedema was mostly mild. It was determined that light touch (but not vibration) was significantly decreased in patients with lymphedema as compared to those without. Using SWM, Civelek [18] found no difference between the affected and unaffected sides of the cases with mild lymphedema after breast cancer treatment. In contrast/addition to these aforementioned reports; several sensory tests (i.e. light touch, static and moving two-point discrimination, PPT and tactile localization) were applied in our study and the patient population comprised patients with moderate to severe lymphedema.

Concerning the possible mechanisms; it has been reported that light touch sensation decreased as the mechanical properties of the skin (e.g. hardness, epidermal thickness and stretch response) increased [19]. It is thought that the decrease in sensory perception of SWM, static and moving two-point discrimination, PPT and tactile localization, together with epidermis, dermis, and subcutaneous fat thicknesses might be related to the decrease in the ability to activate afferent conduction. Increased soft tissue thickness can cause a greater distinction between the mechanoreceptors and the external stimuli, and have a significant effect on afferent firing at the perceptual threshold. In addition, the transmission ability of the stimulus force applied to the skin to activate mechanoreceptors may be affected by skin hardness and thickness [19]. In stage 2 lymphedema, the skin is hard and the godet test is also positive with strong pressure. Moreover, in stage 2 lymphedema, the extremity is enlarged and nerve endings possibly become responsible for a wider area. Therefore, this could be another reason for the decrease in sensation as well. Additionally, peripheral nerve entrapments associated with lymphedema or fibroblast infiltration might also be contributory as regards the eventual sensory disturbance [20].

Stimulating flow through lymphatic vessels and activating the collateral circulation, CDP causes increased fluid and protein emission, softens fibrotic tissues, and improves histological changes associated with lymphedema. Currently, it is the most effective and the gold standard conservative treatment for lymphedema [21, 22]. Auriol et al. [23] reported that skin elasticity increased and soft tissue thickness decreased after CDP. Keser and Esmer [24], examined the acute effects after one session of MLD and found that the PPT and pressure pain tolerance increased in healthy participants. In our study, not only MLD, but all componentss of CDP were applied for three weeks. Additionally, to eliminate the effects of compression on sensation, evaluations were made 30 minutes after the bandages were removed. Of note, it was observed that the PPT perception decreased as lymphedema subsided; in other words, the sensory perceptions improved. CDP softens the skin hardness and decreases soft tissue thickness in lymphedema patients $[15,21]$. Edema reduction and possible/favorable changes in the skin histology might have contributed to the improvement in the sensory parameters. Moreover, CDP treatment provides a high level of sensory inputs to the patients and they might have positively contributed as well.

This study has two major limitations. First, sensory evaluations were acquired from a single region. Herein, since more than one sensory perception was preferred to be assessed in details and as high concentration of the subject is a prerequisite during the assessments, we have taken a single region to 
avoid distraction and inconvenience. Second, due to the current COVID-19 pandemic, both the number of patients who applied for lymphedema treatment and of those who volunteered to participate in our study decreased significantly. Therefore, further studies with larger sample sizes are warranted.

\section{Conclusion}

To conclude, in light of this study findings, we imply that BCRL reduced sensory perceptions of light touch, static and moving two-point discrimination, PPT and tactile localization. Being aware that BCRL is commonplace in daily clinical practice and that sensory disturbances can expose these patients to injuries; it is noteworthy that relevant patients be treated with CDP not only for edema reduction, but also to improve their sensory functions. Further studies with additional sensory evaluations at multiple sites and perhaps coupled with specific electrophysiological correlates are definitely awaited.

\section{Declerations}

\section{Funding:}

This research did not receive any specific grant from funding agencies in the public, commercial, or notfor-profit sectors.

\section{Conflicts of interest:}

The authors decleare no conflicts of interest.

\section{Ethics approval:}

The Hacettepe University Ethical Committee approved the present study (Date: 28.11.2019, No: KA 19120).

\section{Consent to participate:}

Informed consent was obtained from all individual participants included in the study.

\section{Consent for publication:}

Patients signed informed consent regarding publishing their data.

\section{Availability of data and material:}




\section{Code availability:}

$N / A$

\section{Authors' contributions:}

All authors contributed to the study conception and design. Material preparation, data collection and analysis were performed by [Emine Baran], [Levent Özçakar], [Serap Özgül], [Sercan Aksoy] and [Türkan Akbayrak]. The first draft of the manuscript was written by [Emine Baran], [Türkan Akbayrak], and [Levent Özçakar] and all authors commented on previous versions of the manuscript. All authors read and approved the final manuscript.

\section{References}

1. Penn IW, Chang YC, Chuang E, Chen CM, Chung CF, Kuo CY, Chuang TY (2019) Risk factors and prediction model for persistent breast-cancer-related lymphedema: a 5-year cohort study. Support Care Cancer 27(3):991-1000.

2. Smoot B, Wong J, Cooper B, Wanek L, Topp K, Byl N, Dodd M (2010) Upper extremity impairments in women with or without lymphedema following breast cancer treatment. J Cancer Surviv 4(2):167-78.

3. Orhan C, Üzelpasaci E, Baran E, Nakip G, Özgül S, Aksoy S, Akbayrak T (2020) The reliability and validity of the turkish version of the lymphedema life impact scale in patients with breast cancerrelated lymphedema. Cancer Nurs 43(5):375-83.

4. Megens AM, Harris SR, Kim-Sing C, McKenzie DC (2001) Measurement of upper extremity volume in women after axillary dissection for breast cancer. Arch Phys Med Rehabil 82(12):1639-44.

5. Sander AP, Hajer NM, Hemenway K, Miller AC (2002) Upper-extremity volume measurements in women with lymphedema: a comparison of measurements obtained via water displacement with geometrically determined volume. Phys Ther82(12):1201-12.

6. Moberg E (1958) Objective methods for determining the functional value of sensibility in the hand. $J$ Bone Joint Surg $\mathrm{Br}$ 40(3):454-76.

7. Tracey EH, Greene AJ, Doty RL (2012) Optimizing reliability and sensitivity of Semmes-Weinstein monofilaments for establishing point tactile thresholds. Physiol Behav 105(4), 982-986.

8. Moberg E (1990) Two-point discrimination test. A valuable part of hand surgical rehabilitation, eg in tetraplegia. Scand J Rehabil Med 22(3):127-34.

9. Nolan MF (1982) Two-point discrimination assessment in the upper limb in young adult men and women. Phys Ther 62(7):965-9. 
10. Dellon AL (1978) The moving two-point discrimination test: clinical evaluation of the quickly adapting fiber/receptor system. J Hand Surg 3(5):474-81.

11. Granges G, Littlejohn G (1993) Pressure pain threshold in pain-free subjects, in patients with chronic regional pain syndromes, and in patients with fibromyalgia syndrome. Arthritis Rheum 36(5):642-6.

12. Skirven TM, Osterman AL, Fedorczyk J, Amadio PC, Felder S, Shin EK (2020) Rehabilitation of the hand and upper extremity: Elsevier Health Sciences

13. Halnan C, Wright GH (1960) Tactile localization. Brain 83:677-700

14. Tassenoy A, Mey J, Ridder F, Schuerbeeck P, Vanderhasselt T, Lamote J, Lievens P (2011) Postmastectomy lymphoedema: different patterns of fluid distribution visualised by ultrasound imaging compared with magnetic resonance imaging. Physiotherapy 97(3), 234-243.

15. Executive Committee (2016) The diagnosis and treatment of peripheral lymphedema: 2016 consensus document of the International Society of Lymphology. Lymphology 49(4):170-84.

16. Földi M, Földi E, Strößenreuther C, Kubik S (2012) Földi's textbook of lymphology: for physicians and lymphedema therapists: Elsevier Health Sciences

17. Vignes S, Porcher R, Arrault M, Dupuy A (2007) Long-term management of breast cancer-related lymphedema after intensive decongestive physiotherapy. Breast Cancer Res Treat 101(3):285.

18. Civelek $\mathrm{G}$ (2016) Effects of breast cancer related lymphedema on hand muscle strength, hand functions and sensory loss of hand. Cukurova Med JI 41(2):208-16.

19. Strzalkowski ND, Triano JJ, Lam CK, Templeton CA, Bent LR (2015) Thresholds of skin sensitivity are partially influenced by mechanical properties of the skin on the foot sole. Physiol Rep 3(6):e12425.

20. Ganel A, Engel J, Sela M, Brooks M (1979) Nerve entrapments associated with postmastectomy lymphedema. Cancer 44(6):2254-9.

21. Kligman L, Wong RK, Johnston M, Laetsch NS, Supportive Care Guidelines Group of Cancer Care Ontario (2004) The treatment of lymphedema related to breast cancer: a systematic review and evidence summary. Support Care Cancer 12(6):421-431.

22. Bakar Y, Berdici B, Şahin N, Pala ÖO (2014) Lymphedema after breast cancer and its treatment. J Breast Health 10:6-14.

23. Auriol F, Vaillant L, Pelucio-Lopes C, Machet L, Diridollou S, Berson M, et al (1994) Study of cutaneous extensibility in lymphoedema of the lower limbs. Br J Dermatol 131(2):265-9.

24. Keser I, Esmer M (2019) Does manual lymphatic drainage have any effect on pain threshold and tolerance of different body parts? Lymphat Res Biol 17(6):651-4.

\section{Supplementary Files}

This is a list of supplementary files associated with this preprint. Click to download.

- STROBEchecklist.doc 